\title{
THE EFFECT OF MATERNAL ANEMIA ON THE ANTHROPOMETRIC MEASUREMENTS IN FULL- TERM NEONATES
}

\author{
NASMA N AL-HAJJIAH ${ }^{1 *}$, MOHAMMED A ALMKHADREE \\ ${ }^{1}$ Department of Pediatrics, College of Medicine, University of Al-Qadisiyah, Iraq. ${ }^{2}$ Department of Maternity and Children Teaching \\ Hospital, Al-Qadisiyah, Iraq. Email: Nasma.Al-Hagiah@qu.edu.iq
}

Received: 01 February 2018, Revised and Accepted: 20 February 2018

\section{ABSTRACT}

Objective: The current study was performed to understand the effect of maternal anemia and its severity on anthropometric measurement of fullterm neonates.

Methods: In this study, 254 pregnant women were involved in this study. The women with anemia were classified depending on the hemoglobin concentration into three groups of mild (10.9-9.0 g/dl), moderate (8.9-7.0 g/dl), and severe anemia $(<7.0 \mathrm{~g} / \mathrm{dl})$. The anthropometric measurements of the newborns were measured including birth weight, length, and head and chest circumference. Mothers with chronic diseases, preterm neonates, postdate neonates, neonates with congenital anomalies, or critical illnesses had been excluded from the study.

Results: A total of 147 (58\%) mothers had normal hemoglobin levels, and 107 (42\%) mothers were anemic. The newborns were 123 males and 131 females. From the anemic mothers, 59 (55\%) neonates had low weight, and 48 (45\%) neonates had normal weight. In mothers with mild anemia $(n=83), 40(48 \%)$ neonates had low weight. In mothers with moderate anemia $(n=21), 16(76 \%)$ neonates had low weight. In mothers with severe anemia $(n=3)$, all of their neonates had low weight. The current study revealed a statistically significant difference ( $\mathrm{p}=0.002)$ in the anthropometric measurement of the full-term neonates between anemic and non-anemic mothers. There was also a statistically significant difference ( $\mathrm{p}=0.001$ ) in the anthropometric measurement of the full-termed neonates between severely and mildly anemic mothers.

Conclusion: The current study shows that maternal anemia affects the anthropometric measurements of newly delivered full-term neonates. Neonates born to anemic mothers had low birth weight and shorter length than those in neonates who were born to non-anemic mothers.

Keywords: Anemia, Anthropometry, Neonates, Pregnant.

(C) 2018 The Authors. Published by Innovare Academic Sciences Pvt Ltd. This is an open access article under the CC BY license (http://creativecommons. org/licenses/by/4. 0/) DOI: http://dx.doi.org/10.22159/ajpcr.2018.v11i4.25579

\section{INTRODUCTION}

Anemia is deficiency in the numbers of healthy red blood cells and/or the concentration of hemoglobin which can lead to a lack of oxygencarrying ability, causing unusual tiredness. Approximately 51\% of pregnant women are anemic before delivery [1,2]. Anemia is one of the most common consequences related to pregnancy. It is known that there is a large increase in plasma volume relative to red cell mass in almost all pregnancies. This increase in plasma volume is considered of great importance for normal fetal growth and should be passively observed [3]. The WHO identifies anemia in pregnancy when hemoglobin reads of $<11 \mathrm{~g} / \mathrm{dl}$, and it is the point at which a patient is likely to become symptomatic and therapeutic intervention becomes critical [4]. The WHO uses hemoglobin cutoffs to define anemia in pregnant women as $9-11 \mathrm{~g} / \mathrm{dl}$ for mild, 7-9 $\mathrm{g} / \mathrm{dl}$ for moderate, and $7 \mathrm{~g} / \mathrm{dl}$ for severe anemia [2]. Anemia during pregnancy represents a major public health problem in the developing countries that causes high morbidity and mortality rates in women [5]. Iron and/or folic acid deficiency, infectious disease, and genetic disorders increase the incidence rate of anemia [6]. In developing countries, maternal anemia is considered as a risk factor for adverse pregnancy outcome through growth retardation or perinatal death, and it is also responsible for $40-60 \%$ of maternal deaths. Anemia in pregnancy threatens the life of both the mother and the fetus $[7,8]$.

Anthropometric studies in children are important through the periodic measurements of anthropometric variables. These measurements are affected by maternal factors such as maternal anthropometric measurement, maternal clinical conditions, and maternal lifestyle [9]. The science of anthropometry deals with the measurements, and it produces generally appropriate, cheap, and non-aggressive technique for measuring the size, proportions, and human body composition. It imitates health and nutritional status, and it also expects performance, upcoming health, and survival rate [10]. Little information is known about the effects of maternal anemia and its severity on full-term neonates, so this study was done to understand some of these effects on full-term neonates using anthropometry.

\section{METHODS}

\section{Study design and collection of data}

A cross-sectional study was followed. The data were collected between January 1 and June 1, 2017. In this study, 254 pregnant women, 1835 years old, were involved in this study. The women with anemia were classified depending on the hemoglobin concentration into three groups of mild $(10.9-9.0 \mathrm{~g} / \mathrm{dl})$, moderate $(8.9-7.0 \mathrm{~g} / \mathrm{dl})$, and severe anemia $(<7.0 \mathrm{~g} / \mathrm{dl})$. The anthropometric measurements of the newborns were measured including birth weight, length, and head and chest circumference. Mothers with chronic diseases, preterm neonates, postdate neonates, neonates with congenital anomalies, or critical illnesses had been excluded from the study. These individuals attended the Maternity and Children Teaching hospital, Al-Diwaniyah City, Iraq. Full obstetrical history was taken including gravidity, parity and abortion, past medical disease, antenatal care during pregnancy, job, educational level, and residence. Members of the studied groups were informed and instructed about the aim of the study, and their acceptance was obtained before taking samples.

\section{Blood samples}

Blood samples were collected from each mother and before delivery for hemoglobin evaluation by cyanohemoglobin method at the laboratory 
of Maternity and Children Teaching Hospital, Al-Diwaniyah City, Iraq. Four measurements were taken for each baby which are weight, length, and head and chest circumference. These records were performed immediately after birth by two doctors in the delivery room at the same hospital. Weighing of naked babies was done using a digital scale. Length measuring of babies was recorded using infantometer (studiometry). Head circumference measuring was done using non-stretch tape, such as metal tape. Then, passing the tape around the widest part of the head was applied. Finally, recording the largest possible measurement was performed. Three different measurements were taken for each baby and recorded the largest one. Measuring of chest circumference was done in which a baby lies on its back. Using a measuring tape, measuring of chest circumference at the level of the nipples during normal breathing.

Statistical analysis

Analysis of data was carried out using the available statistical package of SPSS-18 (Statistical Packages for the Social Sciences-version 18 "PASW" Statistics). Data were presented in simple measures of frequency, percentage, mean, standard deviation, and range (minimummaximum values). The significance of differences between means (quantitative data) was tested using Student's t-test. While different percentages (qualitative data) were tested using Pearson's Chi-square test. Statistical significance was considered whenever $p<0.05$.

\section{RESULTS}

Mother's hemoglobin status and neonates' birth weight

A total of 147 (58\%) mothers had normal hemoglobin levels, and 107 (42\%) mothers were anemic. The newborns were 123 males and 131 females. From non-anemic women, 38 (26\%) neonates were had low weight, and 109 (74\%) neonates had normal weight. From the anemic mothers, 59 (55\%) neonates had low weight, and 48 (45\%) neonates had normal weight (Table 1).

\section{Birth weight in accordance with the degree of anemia}

In mothers with mild anemia ( $\mathrm{n}=83), 40(48 \%)$ neonates had low weight. In mothers with moderate anemia $(\mathrm{n}=21), 16(76 \%)$ neonates had low weight. In mothers with severe anemia $(n=3)$, all of their neonates had low weight (Fig. 1). There was a statistically significant difference $(p=0.002)$ in the anthropometric measurement of the full-term neonates between

Table 1: Relation between weight for age percentile and hemoglobin of the mothers

\begin{tabular}{lllll}
\hline $\begin{array}{l}\text { Weight for } \\
\text { age percentile }\end{array}$ & $\mathbf{n}(\mathbf{\% )}$ & $\mathbf{p}$ \\
\cline { 2 - 4 } & $\begin{array}{l}\text { Non-anemic } \\
\text { mothers }\end{array}$ & $\begin{array}{l}\text { Anemic } \\
\text { mothers }\end{array}$ & Total & \\
\hline$>97^{\text {th }}$ & $5(3.40)$ & $3(2.80)$ & $8(3)$ & 0.001 \\
$50-97$ & $48(32.60)$ & $21(19.60)$ & $69(27)$ & \\
$3^{\text {rd }}-50^{\text {th }}$ & $56(38.20)$ & $24(22.40)$ & $80(31.40)$ & \\
$<3^{\text {rd }}$ & $38(25.80)$ & $59(55.20)$ & $97(38.60)$ & \\
Total & $147(100)$ & $107(100)$ & $254(100)$ & \\
\hline
\end{tabular}

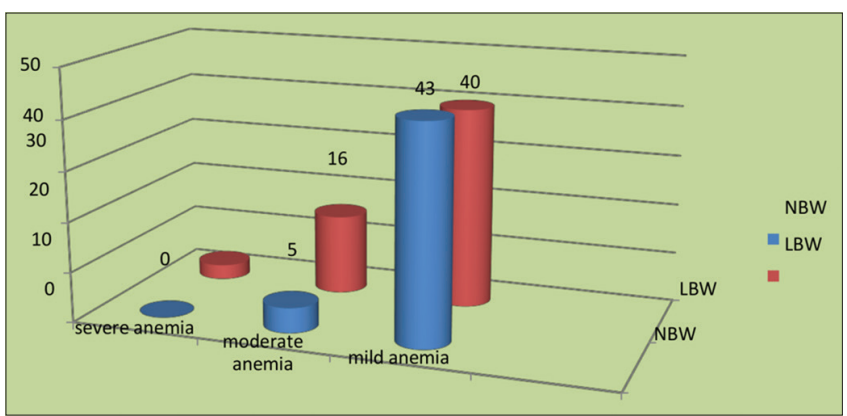

Fig. 1: Birth weight distribution of full-term neonates according to the severity of maternal anemia anemic and non-anemic mothers. The results revealed a statistically significant difference $(p=0.001)$ in the anthropometric measurement of the full-termed neonates between severely and mildly anemic mothers.

Anthropometric measurement of full-term neonates for anemic and non-anemic mothers

The results of current study showed that the length was $1.1 \mathrm{~cm}$, and birth weight was $280 \mathrm{~g}$ of the neonates who were born to anemic mothers. These values were less than those in the neonates who were born to non-anemic mothers. Occipitofrontal circumference (OFC) of full-term neonates who belonged to mothers with anemia were less, $0.19 \mathrm{~cm}$, than that in full-term neonates who belonged to nonanemic mothers. CC of full-term neonates who belonged to mothers with anemia were less, $0.21 \mathrm{~cm}$, than that in in full-term neonates who belonged to non-anemic mothers. The results revealed a statistically significant difference $(p=0.002)$ in the anthropometric measurement of the full-term neonates between anemic and non-anemic mothers.

Anthropometric measurement of full-term neonates among anemic mothers

The results revealed significant difference in the anthropometric measurement of full-term neonates in mother with severe and mild anemia. The results also revealed that the length $(4.7 \mathrm{~cm})$ and birth weight $(750 \mathrm{~g})$ of neonates in mothers with severe anemia were less than in the mothers with mild anemia. The average of OFC of fullterm neonates who belonged to mothers with moderate and severe anemia were less, $0.57 \mathrm{~cm}$, than that average of the full-term neonates who belonged to mothers with mild anemia. The average of CC of fullterm neonates who belonged to mothers with moderate and severe anemia were less, $0.08 \mathrm{~cm}$, than that average of full-term neonates who belonged to mothers with mild anemia, $\mathrm{p}=0.001$.

Correlation between maternal hemoglobin and birth weights of full-term neonates

There was significant correlation between maternal hemoglobin and birth weight of full-term neonates. There was increment in birth weight with the increase in maternal hemoglobin, percentile in non-anemic mothers (Table 2 and Fig. 2).

Correlation between maternal hemoglobin and length of full-term neonates

There was significant correlation between maternal hemoglobin and length of full-term neonates. There was increment in birth length with the increase in maternal hemoglobin (Fig. 3).

\section{Weight for age percentile}

The weight for age percentile was significantly ( $p=0.001)$ affected by maternal anemia, 59\% (55\%) neonates were below the third percentile in anemic mothers while $38(26 \%)$ neonates were below the third percentile in non-anemic mothers (Table 1).

\section{Length for age percentile}

The length for age percentile was significantly $(p=0.02)$ affected by maternal anemia, $11(10.3 \%)$ neonates were below the third percentile in anemic mothers while $2(1.4 \%)$ neonates were below third

\section{DISCUSSION}

Anemia is one of the common predominant nutritious in sufficiency problems affecting pregnant women [11-14]. In this study, a significant decrease was found in anthropometric measurements, weight and length, of full-term neonates who were born to mothers with anemia in comparison to these parameters of babies from non-anemic mothers. The current study results agree with the findings from various studies that found the general occurrence of anemia among pregnant women was assessed to be $72.5 \%, 61.2 \%, 43 \%, 36 \%$, and $13 \%$ in India, Nigeria, Turkey, Bangladesh, and New Zealand, respectively [15-19]. Although these authors detected the same as the current study results, the current study did not find any significant differences at the levels of head and chest circumference. In India, a study showed that maternal hemoglobin 
Table 2: Relation between length for age percentile and hemoglobin of the mothers

\begin{tabular}{|c|c|c|c|c|}
\hline \multirow{2}{*}{$\begin{array}{l}\text { Weight } \\
\text { for age } \\
\text { percentile }\end{array}$} & \multicolumn{3}{|l|}{ n (\%) } & \multirow[t]{2}{*}{$p$ value } \\
\hline & $\begin{array}{l}\text { Non-anemic } \\
\text { mothers }\end{array}$ & $\begin{array}{l}\text { Anemic } \\
\text { mothers }\end{array}$ & Total & \\
\hline$>97^{\text {th }}$ & $2(1.40)$ & $0(0.00)$ & $2(0.80)$ & 0.02 \\
\hline $50-97$ & $62(42.10)$ & $34(31.80)$ & $96(37.80)$ & \\
\hline $3 \mathrm{rd}-50^{\text {th }}$ & $81(55.10)$ & $62(57.90)$ & $143(56.30)$ & \\
\hline$<3^{\text {rd }}$ & $2(1.40)$ & $11(10.30)$ & $13(5.10)$ & \\
\hline Total & $147(100)$ & $107(100)$ & $254(100)$ & \\
\hline
\end{tabular}

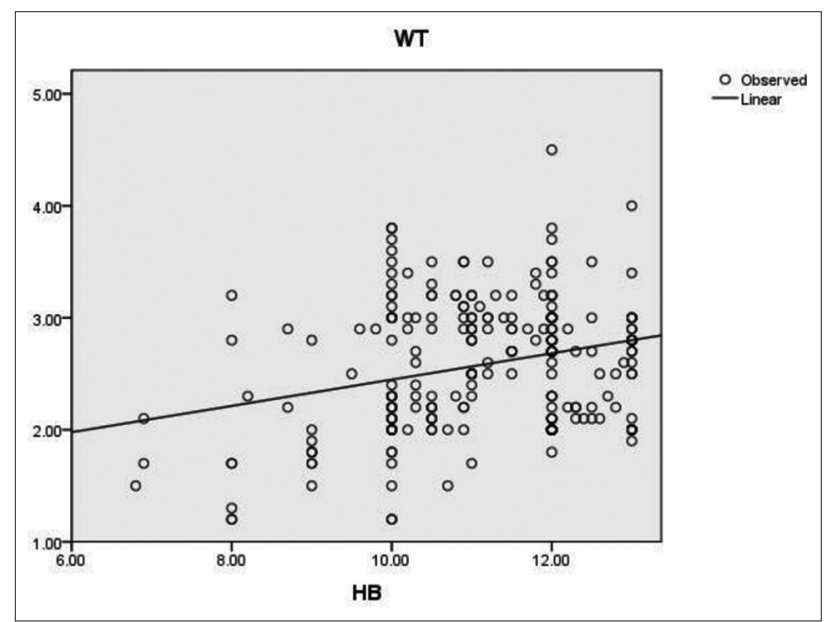

Fig. 2: Correlation between maternal hemoglobin and birth weight

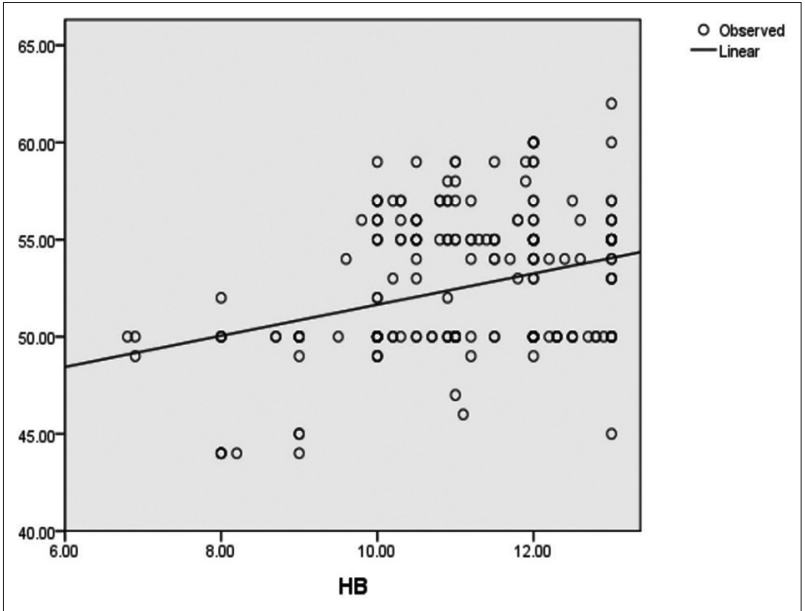

Fig. 3: Correlation between maternal hemoglobin and length of neonates

concentration had statistically significant correlation with birth weight [20], and this agrees with the current study results that found the same correlation. However, studies revealed opposite results when they found no such correlation and effects of anemic mothers on birth weights of neonates [10,21-23]. In Baghdad-Iraq, a study showed that maternal anemia affected birth weight, length, chest circumference, and then head circumference. The study also found that the percentiles of weight and length for age were significantly affected. The percentile of OFC forage was also affected [24], and these results agree with the current study findings.

\section{ACKNOWLEDGMENTS}

The authors wish to the thank the staff of Maternity and Children Teaching hospital, Al-Diwaniyah City, Iraq, for numerous facilities during this work.

\section{CONFLICTS OF INTEREST}

The author declares that there is no competing interest.

\section{REFERENCES}

1. Flemming A. Anemiaduring Pregnancy. Available from: http://www. netdoctor.co.uk/disease/facts/anemia pregnancy. [Last accessed 0n 2014 Jan 04].

2. Galloway R. Anemia preventionandcontrol: What Works. USAID, World Bank, PAHO/WHO, Micronutrient Initiative, FAO, and UNICEF; 2003.

3. Goodlin RC, Dobry CA, Anderson JC, Woods RE, Quaife M. Clinical signs of normal plasma volume expansion during pregnancy. Am J Obstet Gynecol 1983;145:1001-9.

4. Odekunle A, Jacinto S, Burnett M, Clapperton M, David Y, Denis W, et al. Anemia inpregnancy: Associations with parity, abortions and child spacing in primary health care clinic attendees in Trinidad and Tabago. Afr Health Sci 2010;10:66-70.

5. Rosmawti N, Nazri M, Ismail $M$. The rate and risk factors for anemia among pregnantmothers in Jerteh Trengganu, Malaysia. J Community Med Health Educ 2012;2:21.

6. Balarajan Y, Ramakrishnan U, Shankar A, Subramanian S. Anaemia in low-income andmiddle-income countries. Lancet 2011;1

7. Brabin L, Nicholas S, Gogate A, Karande, A, Khanna, R, Dollimore N, et al. A high prevalence of anemia among women in Mumbai, India. Food Nutr Bull 1998;19:205-9.

8. Viteri FE. The consequences of iron deficiency and anemia in pregnancy. Adv Exp Med Biol 1994;352:127-39.

9. Utpala GD, Gregory DS. Abnormal fetal growth: Intrauterine growth retardation, small for gestational age, large for gestational age. In: Davis C, editor. Pediatric Clinics of North America. Philadelphia, PA: WB Saunders; 2004. p. 640-4.

10. Abeysena C, Jayawardana P, de A Seneviratne R. Maternal haemoglobin level at booking visit and its effect on adverse pregnancy outcome. Aust N Z J Obstet Gynaecol 2010;50:423-7.

11. Thangaleela T, Vijayalakshmi P. Prevalence of anemia in pregnancy. Ind J Nutr Diet 1994:31:26-9.

12. Cutner A, Bead R, Harding J. Failed response to treat anemia in pregnancy; Reasons and evaluation. J Obstet Gynecol 1999;Suppl:S23-7.

13. UNICEF/UNU/WHO. Iron Deficiency Anemia: Assessment, Prevention, and Control. A Guide for Program Managres. Geneva, Switzerland: World Health Organization; 2001.

14. Zimmermann MB, Hurrell RF. Nutritional iron deficiency. Lancet 2007;370:511-20.

15. Malhotra M, Sharma JB, Batra S, Sharma S, Murthy NS, Arora R, et al. Maternal and perinatal outcome in varying degrees of anemia. Int $\mathrm{J}$ Gynaecol Obstet 2002;79:93-100.

16. Akinola OI, Fabamwo AO, Tayo AO, Rabiu KA, Abisowo OY, Alokha ME, et al. Maternal hemoglobin and fetal birth weight any relationship? The experience in Lagos, South Western Nigeria. Nigerian Med Pract 2008;54:50-2.

17. Telatar B, Comert S, Vitrinel A, Erginoz E, Akin Y. The effect of maternal anemia on anthropometric measurements of newborns. Saudi Med J 2009;30:409-12.

18. Akhter S, Momen MA, Rahman MM, Parveen T, Karim RK. Effect of maternal anemia on fetal outcome. Mymensingh Med J 2010;19:391-8.

19. Brough L, Rees GA, Crawford MA, Morton RH, Dorman EK. Effect of multiple-micronutrient supplementation on maternal nutrient status, infant birth weight and gestational age at birth in a low-income, multiethnic population. Br J Nutr 2010;104:437-45.

20. Rusia U, Madan N, Agarwal N, Sikka M, Sood SK. Effect of maternal iron deficiency anaemia on foetal outcome. Indian J Pathol Microbiol 1995;38:273-9.

21. Sagen N, Nilsen ST, Kim HC, Bergsjø P, Koller O. Maternal hemoglobin concentration is closely related to birth weight in normal pregnancies. Acta Obstet Gynecol Scand 1984;63:245-8.

22. Kozuki N, Lee AC, Katz J, Child Health Epidemiology Reference Group. Moderate to severe, but not mild, maternal anemia is associated with increased risk of small-for-gestational-age outcomes. J Nutr 2012;142:358-62.

23. Srinivas P, Srinivasan P. The relationship between maternal anemia and birth weight in new born. IOSR J Dent Med Sci (IOSR-JDMS) 2015;14:9-11.

24. Ali SM, Murad AM, Murad AM. Effect of maternal hemoglobin on anthropometric measurements of full term newly born babies. IRAQI J Med Sci 2013;11:2-6. 